\title{
Greetings from Chairperson of the 14th IBRC
}

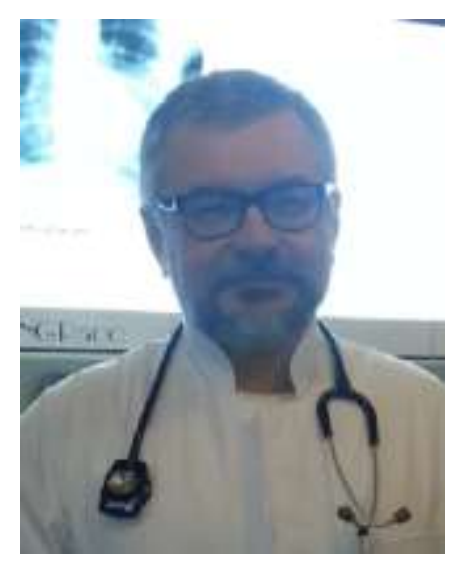

Dariusz Jastrzebski, MD.PhD

Chair of the Organizing Committee of the International Conference "Rehabilitation in XXI Century - Aging and Life Course"

Dear Friends;

It's a great honor and big pleasure for me to invite you to Ustron to take part in the International Conference "Rehabilitation in XXI Century - Aging and Life Course". Thanks of Uzdrowisko Ustron Health Resort which host the conference this year we have the opportunity to meet together in the beautiful Beskid Mountains.

I am sure that amazing views and clean air will be inspiration to fruitful deliberations. This year, first time in the history of Biophilia Academy Conferences separate session was dedicated to cardiopulmonary rehabilitation. While the cardiac rehabilitation is well-founded in everyday practice, the pulmonary rehabilitation is still 'terra incognita" in many fields. Despite the fact, that we start our life and end it with the first and last breath. Dyspnea, cough is common not only in the lung diseases. Especially in the elderly those symptoms become across - the board and substantially worsen the quality of life. I am grateful for Biophilia Academy that this year Pulmonary Rehabilitation gains a chance to become crucial element of that Congress.

I am sure that your scientific enthusiasm will be inspiration for new goals of rehabilitation in the 21st century and happy that "International Conference "Rehabilitation in XXI Century - Aging and Life Course" could be helpful to achieve them.

I wish you a pleasant stay in Ustron

With very kind regards, 